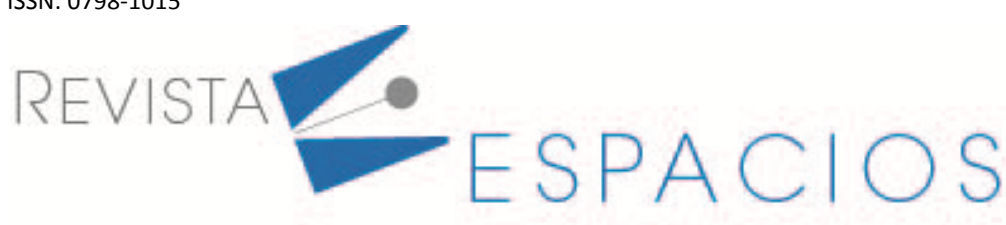

\title{
Portfolios electrónicos de lenguas: un estudio comparativo
}

\section{Electronic language portfolios: a comparative study}

\author{
LUELMO DEL CASTILLO, María José ${ }^{1}$
}

\begin{abstract}
Resumen
El Portfolio Europeo de Lenguas es hoy una herramienta en desuso, aunque en el contexto educativo actual sería deseable contar con un portfolio específico para el aprendizaje de idiomas. Se ha identificado que uno de los aspectos clave que podría contribuir tanto a la reactivación del proyecto como a las buenas prácticas es la creación de portfolios con un formato actualizado. Este artículo analizará diversos e-portfolios de lenguas para poder identificar las características que un potencial nuevo PEL debería tener.

Palabras clave: aprendizaje de lenguas, metodología, portfolios.
\end{abstract}

\begin{abstract}
The European Language Portfolio is nowadays a tool in disuse, although in the current educational context it would be desirable to have a portfolio specially designed for language learning. One of the aspects that have been identified as essential is the development of updated portfolios that could contribute to the reactivation of the project and to the expansion of good practices. This article will analyze language e-portfolios with the objective of identifying the basic characteristics that a potential ELP should have. (dejar en 80)

Key Words: language learning, methodology, portfolios.
\end{abstract}

\section{Introducción}

Estamos asistiendo en los últimos años a la aparición de un nuevo paradigma educativo que propone, entre otras cosas, situar al alumno en el centro del proceso de enseñanza y aprendizaje. Otro de los aspectos novedosos dentro de este nuevo paradigma es que el aprendizaje se articula en torno a competencias en muchos modelos de enseñanza en sus distintos niveles, desde Educación Infantil hasta Educación Superior.

Este contexto lleva consigo una actualización metodológica en las aulas que ha sido promovida desde la administración. Dentro del ámbito universitario, debemos, en primer lugar, mencionar la Declaración de Bolonia y la creación del Espacio Europeo de Educación Superior (EEES) que han supuesto un cambio profundo en los planes de estudio, la metodología y la organización de las universidades en Europa.

El uso de portfolios educativos está cada día más presente en las aulas, puesto que es una herramienta que complementa el trabajo realizado con cualquier otra metodología activa y, además, tiene valor por sí mismo puesto que permite recopilar muestras del trabajo del alumno a la vez que trabaja el desarrollo de la capacidad meta cognitiva promoviendo así que el alumno consiga un mayor grado de autonomía.

${ }^{1}$ Universidad Rey Juan Carlos. Email: mariajose.luelmo@urjc.es 
Con este fin, el Consejo de Europa lanza en 2001 el Portfolio Europeo de Lenguas (PEL) que buscaba dar respuesta a las especificaciones teóricas del Marco Común de Referencia Europeo para las Lenguas (MCER), así como a los retos que implica el paradigma educativo en el que nos encontramos. Esta herramienta se implementa en un total de 32 países europeos durante los años 2001-2011. A pesar de que los resultados obtenidos en los estudios realizados sobre su impacto fueron positivos (Stochieva, Hughes y Speitz, 2009), el Portfolio Europeo de Lenguas es a día de hoy una herramienta en desuso.

Sin embargo, el uso de portfolios de aprendizaje se está extendiendo en distintos ámbitos y resulta contradictorio que una herramienta creada ad hoc para el aprendizaje de lenguas siguiendo los mismos principios que sustentan el aprendizaje a través de portfolios, y, además, los preceptos del Marco Común Europeo de Referencia para las lenguas, haya dejado de utilizarse.

Entre las razones que llevaron a que el uso del PEL fuese disminuyendo, se encuentra el diseño en sí de la herramienta (Little, 2016). Los PEL lanzados en el año 2001 estaban todos en formato papel. Con el paso de los años, se fueron creando nuevas versiones en formato electrónico siguiendo la rígida estructura de los portfolios originales. Poco a poco, y ya después de que el proyecto PEL finalizara como tal, fueron surgiendo nuevos modelos que incluían funcionalidades gracias al avance de las nuevas tecnologías. El presente trabajo tiene como objetivo analizar distintos portfolios de lenguas en formato electrónico con el fin de identificar tanto aspectos imprescindibles como áreas de mejora con vistas al desarrollo de nuevos portfolios de lenguas.

\section{Marco Teórico}

\subsection{Aprendizaje a través de portfolios}

Como hemos apuntado en la introducción, el aprendizaje a través de portfolios se está implementando cada vez en nuestras aulas. Los beneficios que ofrece el trabajo con portfolios son muchos. En primer lugar, Glaser (1990, p.477 en Klenowski, 2012 p.62) afirma que el trabajo con portfolios es especialmente adecuado para el aprendizaje por competencias "Cuando un trabajo de portafolios se construye y evalúa mediante una perspectiva de desarrollo, es posible que consiga captar alguna evidencia de incremento en una competencia". Esto lo convierte en una metodología particularmente interesante dentro del contexto educativo actual en el que el aprendizaje por competencias es la base de los currículos tanto de educación primaria como secundaria y superior.

Rodríguez Sánchez (2011, p.97) enumera multitud de beneficios derivados del aprendizaje a través de portfolios. En primer lugar, hace referencia, como comentábamos anteriormente, al carácter integrador del portfolio, que relaciona de manera clara enseñanza-aprendizaje y evaluación. El hecho de que el portfolio centre proceso en el alumno es también mencionado como uno de sus beneficios. Además, Rodríguez Sánchez refiere que permite un mejor conocimiento de los mecanismos de aprendizaje, adaptar el desarrollo de la materia y el conocimiento del proceso y no solo del producto. El aprendizaje a través de portfolios facilita la individualización de la enseñanza y la respuesta a la diversidad.

Álvarez, Fidalgo, Arias Gundín y Robledo (2009, p.1086) añaden estos otros beneficios: "facilita en el alumnado un aprendizaje reflexivo, crítico, continuado, personalizado, individualizado y consecuentemente significativo. Además, facilita la autogestión, es motivante y potencia el cambio de los hábitos de estudio y la relación entre los diferentes actores del proceso educativo".

En 2001 se presentaba el Portfolio Europeo de Lenguas, herramienta pionera que buscaba implementar todas estas características aplicadas al aprendizaje de lenguas a nivel europeo. 


\subsection{El Portfolio Europeo de Lenguas}

Resulta difícil hablar del Portfolio Europeo de las Lenguas sin hablar del Marco Común de Referencia para las Lenguas, puesto que la historia de ambos va estrechamente relacionada. El germen de ambos (Trim 1997, $p$. 15) se encuentra en la decisión tomada en el simposio celebrado en Rüshlikon en 1971, donde se decide elaborar un sistema de especificaciones transparentes de dominio para el aprendizaje de idiomas en adultos; es decir, se empieza a trabajar sobre lo que daría lugar al Marco Común Europeo de Referencia para las Lenguas. A partir de ese momento, empieza a fraguarse la historia tanto del MCER como del PEL.

A pesar de que ambos documentos nacen con objetivos comunes y de que el PEL se presenta como herramienta práctica de apoyo para poner en práctica los preceptos del Marco, su suerte ha sido muy diferente. Pasados ya casi 20 años desde su lanzamiento, nos encontramos con que planes de estudio, currículos nacionales, libros de texto y certificaciones oficiales han sido adaptadas al Marco. Sin embargo, es difícil encontrar instituciones que sigan utilizando el PEL.

El Portfolio Europeo de las Lenguas en sus orígenes era un documento en papel. Sin embargo, las nuevas tecnologías que empezaban a despuntar entonces y que hacían posible un formato más flexible y accesible parecían ser el futuro de la herramienta. Además, el uso de portfolios electrónicos en diversos ámbitos académicos estaba extendiéndose cada vez más (Haines and van Engen, 2012).

Sin embargo, a pesar de que el aprendizaje a través de portfolios se iba haciendo cada vez más popular en distintas disciplinas, el Portfolio Europeo de Lenguas, tanto en formato electrónico como en papel, no parecía correr la misma suerte. Así lo expresaba Álvarez:

More than a decade since the birth of the ELP, there is not much research data on whether the ELP is adequate for a variety of target groups; on whether it is applicable to diverse contexts; on how culturally transferable different models are; and on what challenges educators face during the creation process of new models. (...) This lack of research on the ways in which the ELP has been developed and used is even more intriguing when compared with the ample academic work undertaken in the area of educational portfolios. (2012, p. 125)

David Little (2016) admitía que, a pesar del gran número de portfolios validados y registrados que formaron parte del proyecto europeo, el PEL no se logró implementar a gran escala en ningún sistema educativo. No obstante, añade Little, el PEL ha tenido un gran impacto en la transformación de currícula, libros de texto y práctica docente.

Resulta paradójico que, una vez demostrado el valor pedagógico del PEL tras su fase piloto (Schärer, 2002) y los años en los que los proyectos de implementación estuvieron activos (Stochieva, Hughes y Speitz, 2009) y tras la aparición del uso de portfolios de aprendizaje en diversos ámbitos educativos, el PEL no haya logrado diseminar e implementar su uso de manera sistemática. Little (2016, p. 166-167) apunta cuatro razones principales para este fracaso:

- El PEL no cumplió la expectativa de ser la píldora mágica (magic bullet) que proporcionara el remedio universal para las dolencias del aprendizaje y enseñanza de idiomas: en muchos países el PEL necesitaba mucho más apoyo del que las autoridades podían proporcionar.

- El enfoque pedagógico del PEL era extraño (alien, lo califica Little) a la mayoría de los sistemas educativos.

- El PEL se encontró con problemas de integración en tres áreas: la mayoría de los modelos PEL no se desarrollaron como parte de una reforma curricular más amplia, por lo que los descriptores de autoevaluación eran difíciles de relacionar con los objetivos del currículo. Además, en la mayoría de los 
centros educativos se trabajaba con un libro de texto, lo que suponía que el PEL fuese una carga extra. Por otra parte, la cultura de autoevaluación y aprendizaje reflexivo que subyace en el PEL eran impensables en muchos sistemas educativos.

- El PEL en sí presenta algunos problemas, tales como la dicotomía entre el uso de lengua meta y el plurilingüismo.

A pesar de esto, Little considera que "the educational ideals on which the CEFR and the ELP are founded have lost nothing of their relevance and urgency" (2016, p. 168), y por ello propone ideas para garantizar un retorno del PEL en buenas condiciones. Entre ellas se encuentran el fomentar aprendizaje de lenguas centrado en el alumno, buscar nuevos modos de implementación que partan de las aulas y se vayan extendiendo a instituciones superiores, que se creen vínculos claros entre currículos y PEL o que se rediseñe la herramienta. Las nuevas tecnologías permiten infinidad de posibilidades a la hora de diseñar portfolios adaptados a cada contexto.

\section{Metodología}

Para el presente estudio se ha elegido una muestra de cuatro e-portfolios de lenguas que han sido analizados teniendo en cuenta aspectos relevantes tanto de diseño como metodológicos. Los portfolios que se han seleccionado han sido ya utilizados durante varios años en instituciones internacionales. Se trata de los portfolios EPOS (Elektronisches Europäisches Portfolio der Sprachen), desarrollado por la Universidad de Bremen, Peppels, creado por la empresa Owik en Holanda, LinguaFolio, diseñado en Oregón y e-PEL+14 desarrollado por el Ministerio de Educación y Ciencia español. Se presentarán estos cuatro portfolios y se realizará una comparativa entre ellos con el fin de identificar elementos necesarios en todos los portfolios de lenguas así como aspectos que necesitarían mejorarse a la hora de planificar nuevos diseños.

\subsection{EPOS}

El Porfolio Europeo de Lenguas en formato electrónico EPOS, fue lanzado en el año 2012 intentado aprovechar las innovaciones tecnológicas que en aquel momento podían facilitar el aprendizaje a través de portfolios, creando una herramienta que ofreciese funcionalidades más modernas, a la vez que se adaptaba a las metodologías activas que empezaban a utilizarse cada vez más. Ya en su primera versión puesta en marcha en 2012, EPOS permitía crear grupos para utilizarlos de forma cooperativa, realizar proyectos de manera conjunta, crear colecciones de trabajos y permitir que otros estudiantes las viesen y comentasen (Fehse, Friedrich y Kühn, 2011, p. 5). A la primera versión de EPOS (1.0) le siguieron las versiones 1.1 (19-06-2013), 1.2 (01-042014), 1.3 (17-10-2015) y 1.4 (30-09-2016), que es la versión que se va a analizar.

Con respecto a su uso, EPOS se desarrolló principalmente como herramienta para apoyar el aprendizaje autónomo que puede tomar forma de diversas maneras. En la Universidad de Bremen, que es donde fue creado, se utiliza como apoyo a un plan de aprendizaje auto-dirigido complementado por tutorías. EPOS puede utilizarse también de manera totalmente autónoma o dentro de un curso de idiomas, puesto que permite crear clases y adoptar rol de alumno o profesor con sus respectivas funciones. Se trata de una herramienta muy versátil que puede adaptarse a situaciones de aprendizaje diferentes (Kühn y Friedich, 2017). A pesar de que no se encuentra disponible actualmente se ha considerado relevante incluirla en el presente estudio dada la variedad de funcionalidades que ofrecía y el gran número de alumnos al que pudo llegar. 


\subsection{Peppels}

Holanda fue pionero en la creación de un PEL interactivo que contaba con propuesta de actividades que los alumnos podían realizar a través de la propia herramienta. No es extraño, por tanto, que hayan sido ellos los primeros en Europa en crear un portfolio tan completo. Peppels se desarrolló en 2007 y se actualizó en 2015. Es un portfolio de apariencia atractiva y moderna que cuenta con muchas funcionalidades. Al igual que LinguaFolio, se comercializa. Actualmente, existen unos 35.000 usuarios Peppels, número considerable si tenemos en cuenta que se trata solo de usuarios en Holanda (T. De Vries, comunicación personal, 6 de febrero 2017). La versión de Peppels que vamos a describir a continuación solo está disponible en holandés.

\subsection{LinguaFolio}

LinguaFolio es el único eportfolio de los analizados en este trabajo que no es un proyecto europeo. Aun así, tanto su diseño como los principios que subyacen son los mismos que los de Portfolio Europeo de Lenguas. LinguaFolio fue creado para alumnos de entre 12 y 18 años y, principalmente, para ser utilizado en institutos de educación secundaria. Actualmente, también se usa en algunas universidades, como la Universidad de Oregón, y en programas intensivos de aprendizaje de lenguas en otras instituciones. Linguafolio cuenta con 60.000 usuarios de los cuales 40.000 han estado activos el último año (S. Knight, comunicación personal, 27 enero 2017).

Lingua Folio está pensado para trabajar con una clase, y el trabajo que se realiza es guiado. Se trata de una herramienta de apoyo del trabajo en el aula que ayuda a desarrollo de estrategias meta-cognitivas:

planificación, monitoreo y autoevaluación. Alumno y profesor se registran en el eportfolio, previo pago de una cuota de dos dólares por alumno, y ya pueden comenzar a trabajar. El profesor y el alumno acceden a una interfaz diferente con distintas funcionalidades.

Se trata de un portfolio en el sentido estricto de la palabra puesto que cuenta con una sección que recoge los datos personales, lo que sería el Pasaporte, otra en la que trabajar con los descriptores de autoevaluación, que sería la Biografía y una última sección donde se alojan las distintas evidencias de aprendizaje con espacio para la reflexión sobre las mismas, el Dossier. Sin embargo, no cuenta con ninguna herramienta que permita el trabajo en grupo, la comunicación con los compañeros o la co-evaluación. La comunicación con el profesor se realiza únicamente con respecto a la autoevaluación que el alumno realiza y el profesor comenta.

\subsection{El e-PEL +14}

E-PEL+14 fue el Portfolio Europeo de lenguas desarrollado por el Ministerio de Educación español durante la puesta en marcha del proyecto europeo del Consejo de Europa. Es la única versión electrónica desarrollada en España con carácter oficial. A día de hoy sigue funcionando y es posible acceder al mismo a través de la creación de una cuenta de usuario a través del siguiente enlace (https://goo.gl/usdYOw).

Esta versión electrónica del Portfolio Europeo de Lenguas replica el formato tradicional en papel que presentaba Pasaporte, Biografía y Dossier, que en este formato pueden rellenarse de manera electrónica y ser exportados a un documento PDF.

\subsection{Análisis comparativo de los portfolios electrónicos}

Una vez presentados los cuatro portfolios de lenguas en formato digital, se va a realizar una comparativa entre ellos. Centraremos esta comparativa en ocho aspectos fundamentales que definen el espíritu de un Portfolio 
Europeo de Lenguas en formato digital. Analizaremos cada una de las características y cómo se desarrollan en cada uno de estos cuatro portfolios.

\subsubsection{Apariencia física}

Lo primero que se observa al abrir una cuenta en un portfolio digital es su aspecto físico. Es importante que este sea atractivo para motivar al alumno a trabajar con él. Además, su uso debe resultar sencillo. El cuadro 1 resume las características del aspecto físico de cada uno de los portfolios con los que se ha trabajado.

Tabla 1

Comparativa apariencia física eportfolios

\begin{tabular}{cccc} 
EPOS & PEPPELS & LINGUAFOLIO & e-PEL+14 \\
\hline - Formato & - Interfaz & - Diseño claro y & - Formato \\
obsoleto por & completa & moderno & obsoleto por \\
tablas & - Diseño limpio & - Intuitivo & tablas \\
- Navegación & - Definido & - Flujo de trabajo & - Sobrecargado \\
sencilla por & - Obtrusivo & definido & - Inconsistente \\
pestañas & & - No fatiga & - Hipertextualidad \\
- Sin flujo de & & - Interdependencia & no clara \\
trabajo & no marcada & - No intuitivo \\
definido & - Pestañas no & \\
- No intuitivo ni & & evidentes & \\
predecible & & \\
- Interfaz & & \\
sobrecargada & & & \\
\hline
\end{tabular}

Fuente: elaboración propia

Como podemos observar en el cuadro resumen, EPOS y el e-PEL+14 presentan un formato obsoleto por tablas, mientras que Peppels y LinguaFolio resultan más modernos.

EPOS propone la navegación por pestañas, lo que resulta sencillo. Sin embargo, el flujo de trabajo no está definido. Los elementos del interfaz no tienen una función intuitiva ni predecible y no queda claro qué secciones son interactivas y cuáles no. EPOS cuenta con muchas funcionalidades y desde el punto de vista pedagógico es un portfolio muy completo. Sin embargo, el diseño da como resultado una herramienta caótica que requiere entrenamiento para poder utilizarse () y que no resulta físicamente muy atractiva. Por esta razón, la Universidad de Bremen organiza webinars de manera regular para formar a los nuevos usuarios.

Al igual que EPOS, el e-PEL+14 cuenta con un diseño por tablas que hoy en día resulta muy obsoleto y su interfaz aparece también sobrecargada con demasiadas opciones. El peso de los elementos en el interfaz no está equilibrado, ni el flujo de trabajo definido. Tampoco está clara la hipertextualidad que existe entre las distintas secciones. El formato es estático e inconsistente, puesto que no es posible predecir el contenido y físicamente es una herramienta muy poco atractiva.

La apariencia física de Peppels es más moderna. El interfaz es completo, pero no está sobrecargado ni causa fatiga, es limpio. El flujo de trabajo está definido y resulta sencillo comenzar a trabajar con este portfolio. La navegabilidad, sin embargo, se ve alterada por un formato obtrusivo, que requiere entrar y salir muchas veces de las distintas secciones. Su aspecto físico en general nos recuerda al de algunas redes sociales, lo que lo hace especialmente atractivo principalmente para los jóvenes, que son su público mayoritario.

Por último, LinguaFolio presenta también un formato moderno y atractivo. Su formato es el más claro, sencillo e intuitivo de los cuatro portfolios que estamos analizando. Su interfaz invita a trabajar con el flujo que el 
equipo de diseño ha querido darle a la herramienta. Sin embargo, las pestañas no son evidentes y el doble scroll lateral añade confusión, dificultando, aunque no de manera grave, la navegación. En líneas generales, se puede decir que, desde el punto de vista del formato, LinguaFolio es el portfolio más atractivo de los cuatro que se están analizando.

\subsubsection{Información Personal}

La información personal del usuario se presenta de manera muy distinta en cada uno de ellos. Hay que tener en cuenta que algunos portfolios cuentan con una comunidad con la que comparten información personal y en otros la comunicación es simplemente profesor-alumno. El cuadro 2 muestra un resumen de cómo se presenta la información personal en cada uno de los eportfolios.

\section{Cuadro 2}

Comparativa información personal eportfolios

\begin{tabular}{llll}
\multicolumn{1}{c}{ EPOS } & \multicolumn{1}{c}{ PEPPELS } & LINGUAFOLIO & e-PEL+14 \\
\hline - Perfil con foto & - Toda una sección de & - Muy breve & - Ficha de datos personales \\
- Información de contacto & presentación & - Perfil: nombre, idiomas y un & que incluye información \\
- Información sobre redes & - Cabecera con rótulo & pequeño párrafo de & sobre idiomas \\
sociales & profesional & presentación & - Pasaporte: información \\
- Cuadro de presentación & - Pasaporte de lenguas & detallada sobre idiomas \\
para redactar & integrado & - No hay información \\
& - Información sobre & personal \\
& experiencia de aprendizaje & - No se puede redactar. \\
& de lenguas & - Este portfolio se puede \\
& - Espacio libre para biografía & descargar y enviar pero no \\
& - Portfolio: galería visual & compartir online \\
& - Lifelog &
\end{tabular}

Fuente: elaboración propia

EPOS tiene la opción de compartir la información personal con todas las personas que utilizan la herramienta. Dado su carácter eminentemente interactivo, es importante que ofrezca la posibilidad de elaborar un perfil de usuario a modo de presentación personal para darse a conocer dentro de la red EPOS. Así, EPOS permite subir una foto, incluir información personal e información sobre redes sociales. Además, existe un cuadro de texto en el que poder redactar lo que el usuario desee sobre sí mismo.

La sección de información personal en Peppels es muy completa. Al igual que EPOS, Peppels también cuenta con una red de usuarios con los que es posible contactar y por ello permite presentar la información personal de forma completa y atractiva. La cabecera principal puede editarse para poder incluir una foto y un rótulo profesional y tiene un enlace al pasaporte de lenguas con toda la información referente a las lenguas que el usuario utiliza o está aprendiendo. A continuación, existe un cuadro para poder redactar de manera libre una pequeña biografía y, para completarla, un portfolio visual que ilustra con imágenes y textos distintos aspectos de la vida del usuario: profesión, intereses, vida académica, etc. Por último, Peppels tiene un lifelog en el que el usuario puede añadir los comentarios o imágenes que desee compartir con su red de amigos dentro de Peppels.

LinguaFolio y e-PEL+14 presentan la información personal del usuario de manera mucho más limitada, porque sus posibilidades de interacción son mucho menores. En el caso de LinguaFolio la información solo la puede ver 
el profesor. Por lo tanto, una pequeña sección con datos personales básicos, información sobre los idiomas que estudia el alumno y un breve párrafo de presentación personal es suficiente.

E-PEL+14 puede descargarse y enviarse por email, pero no permite que nadie tenga acceso a la cuenta de cada usuario. El titular puede enviar su portfolio a quien quiera, pero nadie lo verá en línea. Este portfolio incluye una ficha de datos personales, que incluye información sobre los idiomas del estudiante, pero no permite presentarse de manera redactada ni dar información personal.

\subsubsection{Autoevaluación}

La autoevaluación es una de las estrategias de aprendizaje centrales en el trabajo a través de portfolios, como hemos comentado de manera reiterada a lo largo de este estudio. Por eso, se considera importante analizar cómo aborda cada uno de los cuatro portfolios con los que estamos trabajando la aproximación a la misma. El cuadro 3 muestra una comparativa resumen.

Cuadro 3

Comparativa autoevaluación personal eportfolios

\begin{tabular}{|c|c|c|c|}
\hline EPOS & PEPPELS & LINGUAFOLIO & e-PEL+14 \\
\hline $\begin{array}{l}\text { Distintas secciones } \\
\text { Se realiza autoevaluación } \\
\text { por destrezas y se } \\
\text { establecen objetivos } \\
\text { El trabajo en Pages puede } \\
\text { estar relacionado con } \\
\text { descriptores (o no) } \\
\text { Permite co-evaluación de } \\
\text { compañeros de grupo o } \\
\text { usuarios EPOS }\end{array}$ & $\begin{array}{l}\text { Antes de crear la tarea el } \\
\text { alumno tiene acceso a los } \\
\text { descriptores de } \\
\text { autoevaluación que puede } \\
\text { completar para tener claros } \\
\text { los objetivos de la tarea }\end{array}$ & $\begin{array}{l}\text { Conexión sencilla y directa: } \\
\text { descriptor-trabajo } \\
\text { Todo trabajo que se sube } \\
\text { está relacionado con un } \\
\text { descriptor de } \\
\text { autoevaluación } \\
\text { My proficiency overview } \\
\text { muestra de manera } \\
\text { visualmente muy atractiva } \\
\text { el resultado de las } \\
\text { autoevaluaciones }\end{array}$ & $\begin{array}{l}\text { Click en descriptores } \\
\text { Porcentaje de nivel } \\
\text { conseguido } \\
\text { Muestra resultado en } \\
\text { pasaporte }\end{array}$ \\
\hline
\end{tabular}

Nota: elaboración propia

EPOS, como mencionábamos al realizar su descripción, da mucha importancia a la autoevaluación. Así lo demuestra el hecho de que la sección de autoevaluación cuenta con distintas subsecciones: autoevaluación, autoevaluaciones guardadas (un dossier de autoevaluación) y evaluaciones externas. En la sección de autoevaluación, el alumno tiene acceso a los descriptores y puede autoevaluarse y guardar el resultado que, además de archivarse en la sección Stored Evaluation para poder ver el progreso, se muestra en forma de barra sombreada por destrezas y niveles. A diferencia de lo que ocurre en Peppels y Lingua Folio, el trabajo con los descriptores no está necesariamente relacionado con las tareas de aprendizaje que, en EPOS, se elaboran en la sección Pages. Se trata de secciones separadas sin hipertextualidad. De los cuatro portfolios analizados en este trabajo, EPOS es el único que permite la co-evaluación, muy importante cuando trabajamos en el marco de metodologías activas.

Peppels da el acceso a los descriptores de autoevaluación antes de que el alumno comience a diseñar una tarea de aprendizaje, dando una idea clara de los objetivos que debería perseguir dicha tarea. El alumno se autoevalúa (sí, regular, no) y luego diseña o realiza la tarea propuesta por el profesor. El resultado de esta autoevaluación aparece, igual que en EPOS, reflejado a modo de barra coloreada por niveles y destrezas. De esta forma, Peppels propone un flujo de trabajo más claro y evidencia la relación que debe existir entre los descriptores y la autoevaluación. 
LinguaFolio da un paso más en esta línea y establece una relación directa entre los descriptores de autoevaluación y las tareas de aprendizaje desarrolladas. Cada tarea representa la evidencia de que el alumno es capaz de realizar las funciones descritas en uno o varios descriptores concretos. Es siempre necesario establecer esta conexión entre ambos elementos antes de poder subir las tareas. Además, después de haber subido la evidencia, el alumno tiene la posibilidad de reflexionar de manera libre sobre la misma, puesto que existe un cuadro de diálogo que acompaña a los archivos subidos donde el alumno puede incluir comentarios sobre la realización de la tarea. LinguaFolio requiere siempre de la presencia de un profesor que acompaña y asesora al alumno. El profesor puede revisar y comentar la autoevaluación hecha por el alumno e invitarle a que la reconsidere. La autoevaluación final que queda almacenada en el portfolio es siempre la del alumno y nunca puede ser sustituida por la del profesor, cuya misión es únicamente la de guía. El resultado de la autoevaluación se muestra de manera atractiva en un gráfico interactivo por destrezas y niveles.

E-PEL+14 propone la autoevaluación a través de tablas en las que alumno hace click según su nivel de competencia: sí o no. No existe la posibilidad de un estado intermedio como en el resto de los portfolios: regular o con ayuda. Lo que sí permite es establecer uno o varios descriptores como objetivos de aprendizaje. Esta información se traslada automáticamente al pasaporte para poder reflejar de un vistazo, de nuevo a través de barras sombreadas por destrezas, el nivel de competencia del alumno. Este portfolio es el único que no cuenta con un espacio de trabajo, con lo cual la autoevaluación se realiza de manera aislada, sin ningún tipo de conexión con las tareas de aprendizaje y sin guía, lo que resulta más complejo a la hora de completar el proceso.

\subsubsection{Reflexión}

El aprendizaje reflexivo es un aspecto central en el trabajo con portfolios y dentro del PEL en particular. El cuadro 4 resume cómo se aborda la reflexión en cada uno de los cuatro portfolios objeto de estudio.

Cuadro 4

Comparativa reflexión

\begin{tabular}{|c|c|c|c|}
\hline EPOS & PEPPELS & LINGUAFOLIO & e-PEL+14 \\
\hline $\begin{array}{l}\text { Journals: herramienta de } \\
\text { reflexión libre }\end{array}$ & $\begin{array}{l}\text { Taak: Planificación de } \\
\text { actividades }\end{array}$ & Sección: Reflection & $\begin{array}{l}\text { Aprender a aprender } \\
\text { (estrategias cognitivas) }\end{array}$ \\
\hline & $\begin{array}{l}\text { Werklog: registro de } \\
\text { trabajo en el que se } \\
\text { pueden escribir notas }\end{array}$ & & Actividades de aprendizaje \\
\hline
\end{tabular}

Nota: elaboración propia

EPOS cuenta con una herramienta que tiene como único objetivo la reflexión y que se denomina Journals. Gracias a esta herramienta, el alumno puede crear sus diarios de aprendizaje y permite la redacción libre, lo que fomenta la creatividad y la práctica del idioma, aunque la ausencia de indicaciones puede dificultar el desarrollo adecuado del proceso. Además, EPOS permite que el usuario añada nuevos descriptores a los ya existentes, lo que requiere también de un proceso de reflexión sobre el establecimiento de objetivos.

Cuando el alumno se dispone a elaborar una actividad en Peppels, el sistema le da dos opciones: Taak o Project. Como veíamos en la descripción de Peppels, Project permite desarrollar la actividad directamente en el portfolio y Taak programar las distintas actividades a realizar para conseguir un objetivo. Taak es, por lo tanto, una herramienta de reflexión que ayuda al alumno a planificarse. Además, la sección Werklog permite hacer anotaciones sobre el trabajo realizado, fomentando también la reflexión.

LinguaFolio cuenta con una sección entera que se llama Reflection. Dentro de esta sección, el alumno tiene la posibilidad de reflexionar sobre una tarea de aprendizaje concreto sobre una autoevaluación, dando lugar a un Dossier de reflexión. El carácter de herramienta eminentemente reflexiva de LinguaFolio queda así de manifiesto. 
Por último, e-PEL+14 contiene varias secciones encaminadas a la reflexión. En primer lugar, en la Biografía aparecen dos secciones con este objetivo: Aprender a Aprender y Actividades de aprendizaje. Si bien el trabajo en ambas secciones es bastante limitado por lo estático del mismo, estas dos secciones son muy importantes y deberían formar parte de todos los ePEL. La sección Aprender a Aprender propone la reflexión sobre estrategias cognitivas con el fin de ayudar al alumno a conocer mejor su estilo de aprendizaje y la sección Actividades de Aprendizaje invita al titular del portfolio a registrar las actividades que más le ayudan a aprender, separadas por destrezas.

\subsubsection{Interacción}

Como se comentaba al comenzar este artículo, la Web 2.0 hizo posible la interoperabilidad, el diseño centrado en el usuario y la colaboración en línea, mejorando de manera sustancial la experiencia web. Cuando hablamos de aprender un idioma la interacción es esencial. Recordemos la reflexión de David Little (2016) en la que afirmaba que la manera de aprender una lengua es a través de su uso. El papel de la interacción dentro del e$\mathrm{PEL}$, herramienta para el aprendizaje de lenguas, por lo tanto, también es importante. El cuadro 5 resume de qué manera permite la interacción cada uno de los portfolios descritos.

\begin{tabular}{lccc} 
& \multicolumn{2}{c}{ Cuadro 5} \\
\multicolumn{1}{c}{ EPOS } & $\begin{array}{c}\text { Comparativa resumen interacción } \\
\text { PEPPLES }\end{array}$ & LINGUAFOLIO & e-PEL+14 \\
\hline Pages: co-evaluación & Netwerk & $\begin{array}{c}\text { Solo con el profesor } \\
\text { que comenta las } \\
\text { autoevaluaciones }\end{array}$ & $\begin{array}{c}\text { Solo se puede } \\
\text { exportar y enviar. }\end{array}$ \\
Groups: creados dentro de EPOS & Feedback & & \\
Foro y grupos de discusión & & & \\
Pages de grupo & & \\
Dossier de grupo & & \\
Servicio de mensajería
\end{tabular}

Nota: elaboración propia.

En EPOS la interacción es completa y tiene lugar desde distintas secciones. En primer lugar, recordemos que EPOS permite que exista la co-evaluación a través de Pages y esta sería la primera forma de interacción entre los usuarios EPOS. Además, es posible crear grupos en los que los usuarios pueden participar, de la misma manera que se hace en las redes sociales. Los grupos permiten la creación de foros de discusión, de un dossier común y de una sección Pages dentro del grupo lo que posibilita el trabajo colaborativo.

Peppels también cuenta con una red social, pero más limitada. Es posible añadir a otros usuarios como amigos, ver su perfil y su actividad a través del Lifelog, pero no es posible el trabajo colaborativo con ellos. La herramienta Feedback permite la interacción con el profesor. Por último, a través de Project el profesor puede proponer actividades para su realización a través de las cuales puede interactuar con el alumno.

E-PEL+14 no permite interacción alguna. Simplemente es posible generar un archivo PDF para su envío, pero que no podrá ser modificado por el receptor. Es una herramienta cerrada y solo visible para el titular.

\subsubsection{Espacio de trabajo}

Gracias también a la web 2.0 ha sido posible crear entornos de trabajo en los ePEL. El dotar los portfolios de este tipo de espacio ha hecho más clara la relación existente entre los descriptores de autoevaluación y las tareas de aprendizaje, consiguiendo de esta forma que el alumno aprenda de manera más eficaz a autoevaluarse y consiga más autonomía. El cuadro 6 resume las características de los espacios de trabajo de los cuatro portfolios descritos. 
Cuadro 6

Comparativa Espacio de trabajo

EPOS

$\begin{array}{ll}\text { Pages } & \text { Project: pueden ser creados por el profesor o } \\ \text { por el alumno }\end{array}$

por el alumno

LINGUAFOLIO

Permite subir archivos de todo tipo y crear: redactar, grabar audio y video directamente, subir enlaces

Espacio para: descripción, cuadro de texto

editable, se pueden adjuntar archivos

Colgarlo para su revisión, acabado

Con fecha y relacionado con una destreza

Nota: elaboración propia

La herramienta Pages de EPOS es la que ofrece un lugar de trabajo en el que el alumno puede desarrollar aquellas actividades que desee. Permite la creación de una página a la que pueden añadírsele muchas funcionalidades (journals, goals, resumee, notes, personal information), lo que permite realizar un trabajo flexible y completo. Es posible también adjuntar archivos o incrustar elementos multimedia.

Peppels también ofrece un espacio de trabajo, Projects, que puede utilizarse de dos formas diferentes. Por un lado, el alumno puede diseñar sus actividades de aprendizaje y llevarlas a cabo en el mismo espacio. Por otro, el profesor puede diseñar las actividades y colgarlas para que el alumno las realice. Projects incluye un espacio para la descripción de la actividad, un cuadro de texto editable con distintas opciones y la posibilidad de adjuntar archivos. Las tareas pueden marcarse como pendientes, listas para evaluar o completadas. Cuando la tarea se marca como completada, con evaluación hecha, pasa a alojarse en Archief, es decir, en el dossier.

El espacio de trabajo de LinguaFolio posibilita subir todo tipo de archivos o crearlos allí mismo. Es el único eportfolio de los que están siendo analizados que permite la grabación de audio o video directamente sin necesidad de cargar archivos. Se pueden crear archivos multimedia de manera externa y subirlos, pero si se decide optar por las herramientas incrustadas en LinguaFolio, estas solo permiten la creación de archivos de video, audio, texto o incrustar un enlace de manera independiente. Los alumnos utilizan este espacio para enviar al profesor sus evidencias de aprendizaje.

A diferencia de los otros tres portfolios, e-PEL+14 no cuenta con espacio de trabajo.

\subsubsection{Multiculturalidad/Plurilingüismo}

La última característica que vamos a analizar es el aspecto multicultural y plurilingüe, que formaba parte esencial del espíritu del PEL desde sus orígenes. El cuadro 7 muestra la comparativa entre los cuatro eportfolios.

Cuadro 7

Comparativa Multiculturalidad y Plurilingüismo

\begin{tabular}{|c|c|c|c|}
\hline EPOS & PEPPELS & LINGUAFOLIO & e-PEL+14 \\
\hline $\begin{array}{l}\text { Hay comunidad EPOS, que } \\
\text { indirectamente es una } \\
\text { forma de fomentar } \\
\text { plurilingüismo }\end{array}$ & $\begin{array}{l}\text { Hay comunidad Peppels } \\
\text { En el pasaporte hay } \\
\text { reflexión sobre experiencias } \\
\text { de aprendizaje en otros } \\
\text { países }\end{array}$ & No existe & $\begin{array}{l}\text { Descriptores de } \\
\text { interculturalidad y } \\
\text { plurilingüismo. }\end{array}$ \\
\hline
\end{tabular}

Nota: elaboración propia

Como puede observarse en la tabla 7, el único ePEL que cuenta con una sección específica de Multiculturalidad y plurilingüismo es e-PEL+14. Esta sección simplemente incluye descriptores en los que el alumno puede hacer 
click si considera que tiene la competencia que describen, pero esto ayuda a concienciar al titular sobre estos aspectos y es importante que esta sección exista.

EPOS y Peppels no cuentan con una sección de este tipo, pero al tener una comunidad que puede ser internacional, sí que se fomenta el plurilingüismo y se hace evidente la multiculturalidad. LinguaFolio no tiene este aspecto en cuenta en absoluto. Es importante recordar que este portfolio no es de un PEL propiamente dicho puesto que su contexto no es europeo y, por lo tanto, las necesidades a las que atiende son diferentes.

\section{Discusión}

El Portfolio Europeo de Lenguas se planteaba como un proyecto de implementación masiva a nivel europeo. Sin embargo, no parece haber sido así. En 2012 ya no existía un seguimiento regular sobre los proyectos y no era posible conocer su alcance ni su impacto. Así lo admitía Little:

ELP contact persons in Council of Europe member states often have no way of knowing how many ELPs have been distributed, how may are in regular use, and what kind of impact the ELP has had on learner, teachers and other language education stake holders (2012, p.11).

Ralf Schärer, relator general del Consejo de Europa para el Proyecto, comentaba que era necesario mantener el esfuerzo y el apoyo para poder continuar con el proyecto y conseguir la implementación a gran escala: "pace seems generally slower than anticipated and it is becoming clear that effort and support over a prolonged period are still needed for widespread implementation" $(2012$, p.53).

Kühn y Cavana, desarrolladoras de EPOS, mencionaban también que el PEL tampoco había parecido tener demasiada repercusión en la literatura especializada: "Precisely due to its innovative nature, the ELP is still far from being widely established as a current instrument of teaching and learning within formal educational settings; nor has it received enough acknowledgement and resonance in educational research literature" (2012, p.2).

Sin embargo, a pesar de que no se ha conseguido implementar el PEL de la manera prevista, su utilidad sigue estando de manifiesto. Kohonen así lo afirma: "The ELP has a great deal of potential for becoming a valuable resource in making the pedagogical journey possible, manageable and rewarding for participants" (2012, p.39).

Algunos autores afirman que sería necesario ajustar los tiempos para que el proyecto pudiese ganar entidad. Schärer explica que el ritmo propuesto para el uso extendido del PEL quizá no fuese realista:

Projects generally have a beginning and an end-man-made timelines to organize and control the speed of action. Yet, processes also have natural timelines-their own pulses and dynamics. The two rarely coincide. This applies to the ELP scheme at the European level and to national, regional and institutional projects. (Schärer, 2012, p.54)

En la misma línea, Little comenta también que quizá el proyecto llegase antes de que se estuviera preparado para él. "Like other Council of Europe innovations, the ELP has sometimes seemed to run ahead of the educational mainstream-perhaps only now, twenty years after it was conceived and ten years after it was launched, the mainstream is beginning to catch up" (2012, p.19). En efecto, el PEL requería de una metodología de trabajo que, en 1998, cuando se comenzó con el proyecto piloto, era difícil de implantar: autonomía, cambio de roles en profesores y alumnos, autoevaluación, aprendizaje reflexivo, etc. La llegada de las metodologías activas, que apoyaban este cambio desde cada paso de su trabajo con ellas, y no a través de una herramienta aislada como parecía ser al principio el PEL, ha contribuido de manera muy positiva a que esta metodología ya 
no resulte tan difícil de adoptar. Por eso creemos que hoy en día la implementación del PEL podría volverse a retomar con éxito y para ello es esencial una actualización de la herramienta.

A día de hoy existen multitud de plataformas electrónicas que permitirían un desarrollo atractivo y eficaz de un nuevo Portfolio Europeo de Lenguas. En efecto, Little (2020) afirma que es necesario rediseñar el Portfolio Europeo de Lenguas adaptándolo a cada contexto y que, a día de hoy, la divisón tradicional en Pasaporte, Biografía y Dossier no resulta esencial : "it is a moot question" (p.15). Sería posible un diseño mucho más flexible, a soft-portfolio (Kühn y Pérez-Cavana, 2012) que pudiera contar con todas las características mejoradas que se presentan en este artículo.

Se plantea como propuesta de futuro el desarrollo completo de un ePEL con el que poder comenzar a trabajar de nuevo. La implementación del PEL o de cualquier otro portfolio de aprendizaje, no tendrá éxito si no contamos con una herramienta adecuada. En efecto, Little (2020) afirma que es necesario rediseñar el Portfolio Europeo de Lenguas adaptándolo a cada contexto y que, a día de hoy, la divisón tradicional en Pasaporte, Biografía y Dossier no resulta esencial : "it is a moot question" (p.15). Sería posible un diseño mucho más flexible, a softportfolio (Kühn y Pérez-Cavana, 2012). Las nuevas tecnologías permiten el desarrollo de funcionalidades que hoy en día son esenciales si se quiere desarrollar una herramienta útil y atractiva. La interacción, la creación de una comunidad o red social, la posibilidad de chatear con otros usuarios, de compartir tareas o experiencias, crear tareas dentro de la propia herramienta, etc. son características factibles en un portfolio digital hoy en día y pueden contribuir no solo hacerlo más atractivo sino a conseguir que el trabajo del alumno con el PEL o con cualquier otro portfolio de lenguas, consiga sus objetivos de manera más sencilla: fomentar su autonomía y el aprendizaje durante toda la vida.

\section{Referencias bibliográficas}

Álvarez, I. (2012). From paper to the web. En B. Kühn, \& M. Pérez Cavana, Perspectives from the European Language Portfolio (págs. 125-142). Oxo: Routledge.

Álvarez, L., Fidalgo, R., Arias-Gundín, O., \& Robledo, P. (2009). La eficacia de las metodologías activas en el rendimiento del alumnado de magisterio. Actas do Congreso Internacional Galego-Portugués de Psicopedagogía (págs. 1083-1094). Braga: Universidade do Minho.

Benito, A., \& Cruz, A. (2007). Nuevas claves para la Docencia Universitaria. Madrid: Narcea.

Haines, K., \& van Engen, J. (2012). Re-conceptualizing the ELP as a Web 2.0 Personal Language Learning Environment. Cercles, 129-144.

Friedrich, J. (2013). MAGICC and EPOS-ePortfolio Systems for Slef-directed Language Learning in Higher Education. 11th Portfolio and Identity Conference (págs. 183-184). London: Adpios.

Fehse, R., Friedrich, J, \& Kühn, B. (2011). EPOS, an ePortfolio for Language Learning. ICT for Language Learning. 4th Edition. Florencia: Simonelli Editori.

Kühn, B., \& Friedich, J. (24 de 01 de 2017). Understanding EPOS. Bremen, Alemania.

Kühn, B., \& Cavana, M. L. P. (Eds.). (2012). Perspectives from the European language portfolio: Learner autonomy and self-assessment. Routledge.

Klenowski, V. (2012). Desarrollo del Portafolios para el aprendizaje y la evaluación. Madrid: Narcea. 
Kohonen, V. (2012): Developing autonomy through ELP-oriented pedagogy: exploring the interplay of shallow and deep structures in a major change in language education, in: Kühn, B. / Pérez Cavana, L. (eds): Perspectives from the European Language Portfolio, London: Routledge, 22-42.

Little, D. (2012). The European Language Portfolio: history, key concerns, future prospects. En B. Kühn, \& M. Pérez Cavana, Perspectives from the European Language Portfolio (págs. 7-21). Oxon: Routledge.

Little, D. (2016). The European Language portfolio: Time for a fresh start? International Online Journal of Education and Teaching, 162-172.

Little, D. (2020). The European Language Portfolio: Past Success, Present Reality, Future Prospects. Portfolioarbeit im Kontext von Sprachenunterricht. Neue internationale Entwicklungen. En Bärbel Kühn \& Sandra Ballweg (eds.) Portfolioarbeit im Kontext von Sprachenunterricht (págs. 17-37). Göttingen: Universitätsverlag Göttingen.

Palomares Ruiz, A. (2011). El modelo docente universitario y el uso de nuevas metodologías en la enseñanza, aprendizaje y evaluación. Revista de Educación, 591-604.

Paulson, F., Paulson, P. and Meyer, A. (1991). What Makes a Portfolio a Portfolio?, Educational Leadership, 48 (5), 60-63.

Rodríguez Sánchez, M. (2011). Metodologías docentes en el EEES: de la clase magistral al portafolio. Tendencias Pedagógicas, 83-103.

Schärer, R. (2002). Final Report: A European Language Portfolio Pilot Project Phase. 1998-2000. Strasbourgh: Council for Cultural Cooperation Commitee.

Schärer. (2012). Twenty years of a common European project. En B. Kühn, \& M. Pérez Cavana, Perspectives from the European Language Portfolio (págs. 46-58). Oxo: Routledge.

Stoicheva, M., Hughes, G., \& Speitz, H. (2009). The European Language Portfolio: An Impact Study. Estrasburgo: Council of Europe.

Trim, J. (1997). Modern Languages in the Council of Europe 1954-1997. International cooperation in support of lifelong language learning for effective communication, mutual cultural enrichment and democratic citizenship in Europe. Strasbourg: Council of Europe Language Policy Division.

Esta obra está bajo una Licencia Creative Commons Attribución-NoCommercial 4.0 International

\section{(cc) EY-NC}

